\title{
Mitochondrial Dysfunction Contributes to Ehlers-Danlos Syndrome - A Patient Presentation
}

\author{
Golder N. Wilson (Corresponding author) \\ Department of Pediatrics, Texas Tech University Health Science Center, Lubbock and \\ KinderGenome Medical Genetics, Dallas
}

\begin{abstract}
Vijay S Tonk
Departments of Pediatrics, Obstetrics \& Gynecology, and Pathology, Texas Tech University Health Science Center, Lubbock TX, USA. Email: vijay.tonk@ttuhsc.edu
\end{abstract}

Received: Aug. 13, $2020 \quad$ Accepted: Sep. 11, 2020

doi:10.5296/jbls.v11i2.17756 URL: https://doi.org/10.5296/jbls.v11i2.17756

\begin{abstract}
A female patient with substantial history and physical findings of Ehlers-Danlos syndrome by systematic evaluation had a variant in the gene encoding the sixth subunit of mitochondrial ATP synthetase gene that produced a change from glycine to aspartic acid at position 132 of the MT-ATP6 protein (MT-ATP6 m.8921G>A, p.Gly132Asp). The mutation was heteroplasmic, affecting $32 \%$ of the mitochondria in blood leucocytes, was qualified as a pathogenic variant because of its significant molecular change, but was not detected in the maternal blood sample as might be expected for its low degree of heteroplasmy. The patient was shown to have typical findings of Ehlers-Danlos syndrome by comparison of 48 history and physical findings in her and a peer group of 32 teenage females with that diagnosis. None of the classical neurosensory or developmental symptoms of mitochondrial disease were present in mother or daughter, but the patient had symptoms, metabolite alterations during rest or exercise, and muscle biopsy changes that suggested mild mitochondrial dysfunction. She also had heterozygous variants of uncertain significance in the nuclear PLOD1, FLNA, and ATP2A genes by concomitant whole exome sequencing that could also contribute to her arthritis-adrenaline disorder. Mitochondrial dysfunction is proposed to influence neuromuscular components of connective tissue, acting through an articulo-autonomic dysplasia cycle to cause the typical joint-skin laxity and dysautonomia of Ehlers-Danlos syndrome.
\end{abstract}

Keywords: Ehlers-Danlos syndrome, mitochondrial DNA, mitochondrial disease, mitochondrial ATP synthase (MT-ATP) gene, connective tissue dysplasia, dysautonomia, arthritis-adrenaline disorder, articulo-autonomic dysplasia 


\section{Introduction}

Genomic testing is dramatically expanding the numbers of genes associated with disease, particularly when applied to more common disease spectra like Ehlers-Danlos syndrome (EDS) and other heritable disorders of connective tissue (Malfait, et al., 2017; Tinkle and Levy, 2019; Weerakkody, et al., 2016; Wilson, 2015; Wilson, 2019a). These conditions, like diabetes or the more common birth defects, are caused by the interaction of multiple genes and environmental factors (multifactorial determination-Wilson, 2019b). The genetic component can now be examined by NextGen or massive parallel DNA sequencing (Teer and Mullikin, 2010; Yang, et al., 2013; Wilson, 2014). This technology simultaneously determines the DNA nucleotide sequence of all targeted genomic regions in the manner of reading all book pages at once rather than beginning to end. Whole exome sequencing (WES) targets all 23,000-plus protein-coding regions (gene segments or exons) of the human genome and can be complemented by mitochondrial DNA sequencing that looks at the 37 within mitochondria DNA (Wilson, 2019a). The combined approach allows timely and affordable detection of protein/RNA-coding changes that may be associated with disease.

Although EDS began as a rare clinical pattern or syndrome highlighted by circus extremes of joint and skin hyperextensibility, it is now recognized to affect a substantial portion of the $10-20 \%$ of patients who have greater than average flexibility. Increased flexibility can be objectively measured by four bilateral maneuvers (fifth finger bend, thumb to forearm, knee and elbow hyperextension) plus the touch palms to floor maneuver of Beighton scale (Wilson, $2019 \mathrm{~b}$ ), those able to perform 5 or more of these characterized as hypermobile. The 1-2\% of the population who develop distress and disease from lax connective tissue have many under-recognized problems that arise from reciprocal imbalance of the autonomic nervous system as diagrammed in Fig. 1.

Tissue laxity not only causes the external findings of joint hypermobility and skin elasticity described by Ehlers and Danlos but also the more subtle blood vessel distensibility that leads to lower body blood pooling and decreased brain circulation (top and right of Fig. 1). Reflexive adrenergic stimulation to elevate heart rate/blood pressure and restore cerebral circulation alters small nerve fibers in connective tissue to lower neuromuscular constraint and increase tissue laxity (bottom and left of Fig. 1). These reciprocal tissue laxity and autonomic processes act as an 'articulo-autonomic dysplasia' cycle, producing a pattern of skeletal and dysautonomia complications that are best identified by the term 'arthritis-adrenaline disorder,' AAD abbreviating both pathogenic process and disease category.

Multiple genes and environmental factors act upon the AAD cycle to produce the findings of tissue laxity (joint hypermobility and subluxation, joint pain, skin elasticity, scoliosis, flat feet) that are more typical of EDS than of other connective tissue dysplasias (charted above the cycle in Fig. 1). Better appreciated by use of standard forms (Wilson, 2019b) are the associated autonomic findings from irritable bowel syndrome, postural orthostatic tachycardia syndrome, and mast cell activation disorder (charted below the cycle in Fig. 1). Whole exome sequencing has supported the AAD concept by adding collagen type XII genes 


\section{Macrothink Institute ${ }^{\mathrm{TM}}$}

that impact muscle or mitochondrial polymerase gamma genes (Stewart, et al., 2008) that impact the autonomic system to collagen type III or V genes associated with tissue laxity in EDS (Wilson, 2019a). Here we further expand the genetic causes of EDS by presenting a patient with typical findings who had a change in the sixth component of the mitochondrial ATP synthase (MT-ATP6) gene (Burrage, et al., 2014).

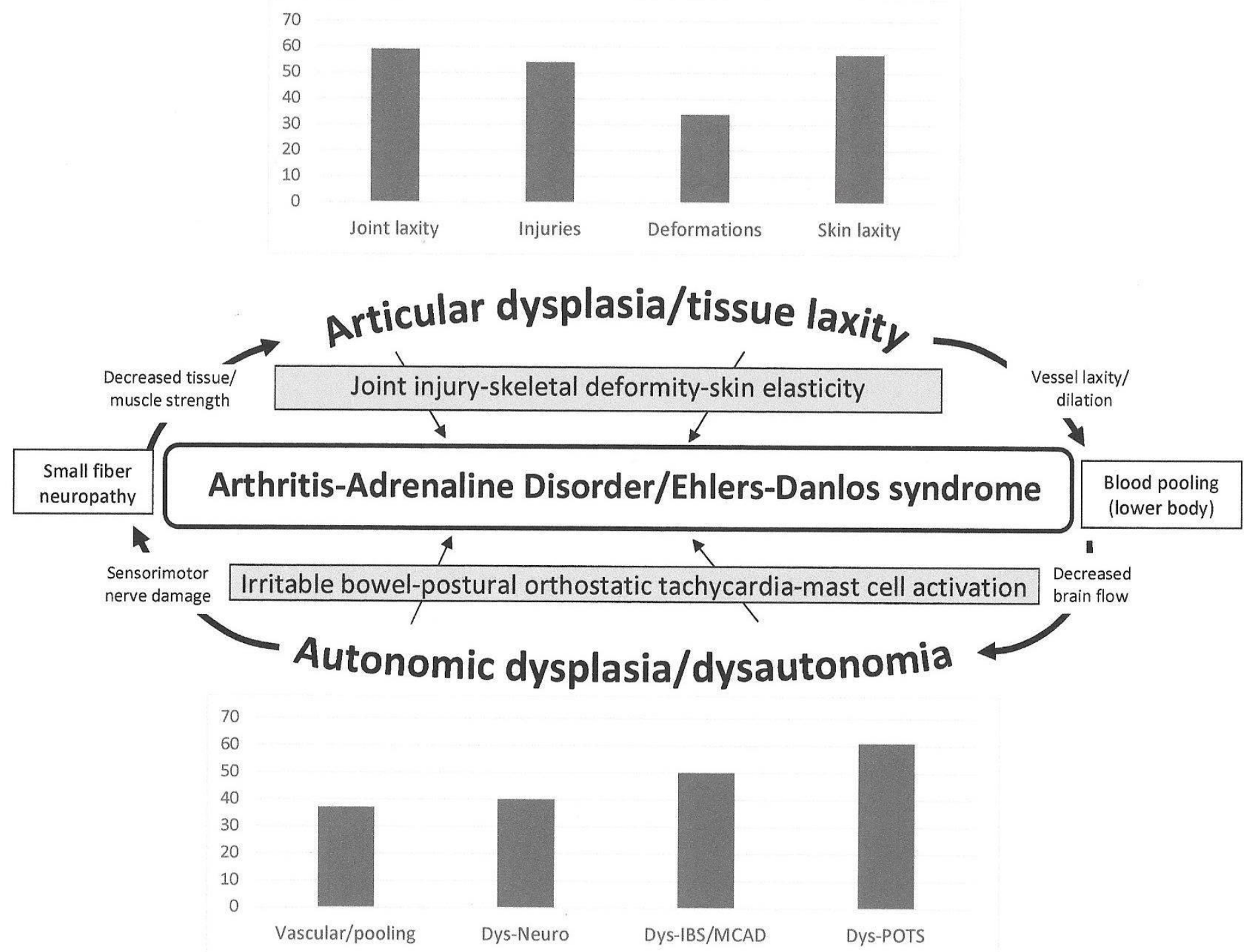

Fig. 1. Characteristic findings of arthritis-adrenaline disorder/Ehlers-Danlos syndrome as produced by an articulo-autonomic dysplasia cycle

Joint and tissue laxity shown above leads to vessel distensibility with lower body blood pooling and reactive adrenergic to restore brain circulation (right). The adrenergic stimulation in turn leads to sensorimotor nerve (Neuro) changes in connective tissue that enhance tissue laxity (right). These reciprocal processes produce tissue laxity (above) and vascular/dysautonomia (Dys) findings (below), their percentages in adolescent females graphed from Table 2 . 


\section{Methods}

History and physical forms were designed to include 80 history and 40 physical findings found frequently in 946 EDS patient evaluations, then used for systematic evaluations of a subsequent 596 females and 114 males (Wilson, 2019b). Average numbers of total findings or of those for organ systems or body regions defined likelihoods of EDS diagnosis and allied complication risks as described previously (Wilson, 2019a, 2019b). History and physical findings that were arranged chronologically for questionnaire convenience could then be grouped into 4 tissue laxity and 4 vascular-dysautonomia categories of 6 measures each as shown in Results.

Whole exome sequencing was performed by the GeneDx Company $@$ using standard methods (Yang, et al., 2013). Coordination of blood/cheek swab sampling and consenting for release of incidental findings and anonymous publication of results was performed by their genetic counselors, results and further counseling conveyed by the ordering medical geneticist (Wilson, 2019a). All but the EDS evaluation was ordered or conducted by other physicians and is presented from records provided by the family.

\section{Results}

\section{Clinical report}

A 16-year-old female came to genetics clinic with her mother for evaluation of possible Ehlers-Danlos syndrome and interpretation of DNA changes found by genomic analyses. They reported 40 of 80 characteristic history findings, a number at the $67 \%$ centile for 596 women systematically evaluated for EDS (Wilson, 2019b). Her clinical course is summarized in Table 1, symptoms beginning with colic during infancy and clumsiness with frequent falls as a toddler. Flexibility was recognized by her parents early on and then by the patient, especially when various adolescent sports activities were limited by pain and fatigue - mainly progressive motor fatigue with muscle cramping. She needed glasses for myopia by age 7 and orthodontics for dental crowding by age 12. She noted popping of her joints in later childhood and has had subluxations of her shoulders with increasing pain in her neck and shoulders. She has had 5 fractures involving her shoulder, elbow, wrist, hand, foot and has recently been noted to have mild scoliosis and pectus excavatum. 
Table 1. Patient laboratory tests

\begin{tabular}{|c|c|c|}
\hline Age & Test & Results \\
\hline $\begin{array}{l}15 \mathrm{yrs} . \\
0 \mathrm{mos} .\end{array}$ & $\begin{array}{l}\text { Mt DNA } \\
\text { sequencing, blood }\end{array}$ & $\begin{array}{l}\text { m.8921 G>A p.Gly132Asp in the sixth component of the mitochondrial DNA } \\
\text { ATP synthase (MT-ATP) gene, heteroplasmic in } 23 \% \text { of leucocyte } \\
\text { mitochondria, not detected in mother and qualified as a likely pathogenic } \\
\text { variant; not reported previously as pathogenic or benign (Mitomap, } \\
\text { www.mitomap.org), present in } 2 \text { of } 30,182 \text { persons in Mitowheel database } \\
\text { (http://mitowheel/mitowheel.html). }\end{array}$ \\
\hline \multirow{3}{*}{$\begin{array}{l}15 \text { yrs. } \\
0 \text { mos. }\end{array}$} & \multirow{3}{*}{$\begin{array}{l}\text { Whole exome } \\
\text { sequencing, blood }\end{array}$} & $\begin{array}{l}\text { c.535A }>\mathrm{G} \text { p.Asp } 179 \text { His variant in the procollagen lysine hydroxylase } \\
(P L O D 1) \text { gene, heterozygous, inherited from father, not reported previously or } \\
\text { seen in normal people. }\end{array}$ \\
\hline & & $\begin{array}{l}\text { c. } 7450 \mathrm{C}>\mathrm{T} \text { p.Arg } 2476 \mathrm{Cys} \text { variant (rs782557713) in the filamin A (FLNA) } \\
\text { gene, heterozygous, inherited from mother, qualified as a variant of uncertain } \\
\text { significance. Previously reported twice as benign, once as variant of uncertain } \\
\text { significance, present in } 21 \text { of } 91599 \text { alleles in non-Finnish Europeans. }{ }^{5}\end{array}$ \\
\hline & & $\begin{array}{l}\text { c. } 1410 C>\mathrm{G} \text { p.Asp } 470 \text { Glu variant (rs533400580) in the alpha-2 polypeptide of } \\
\text { the sodium/potassium transporting ATPase }(A T P 1 A 2) \text { gene, heterozygous, } \\
\text { inherited from mother, qualified and previously reported as a variant of } \\
\text { uncertain significance, present in } 1 \text { of } 251196 \text { alleles (Latino patient) in } \\
\text { Gnomad. }\end{array}$ \\
\hline $\begin{array}{l}15 \text { yrs. } \\
10 \mathrm{mos} .\end{array}$ & $\begin{array}{l}\text { Mt DNA qPCR } \\
\text { analysis; }{ }^{2} \\
\text { Quadriceps muscle }\end{array}$ & $\begin{array}{l}\text { The } 4566 \text { value for mitochondrial abundance was } 93 \% \text { of the control ( } 4933 \\
\pm 777) \text {, mitochondrial depletion syndromes averaging } 6-50 \% \text { of control } \\
\text { abundance in muscle. }\end{array}$ \\
\hline $\begin{array}{l}15 \text { yrs. } \\
10 \text { mos. }\end{array}$ & $\begin{array}{l}\text { Mt respiratory } \\
\text { chain analysis }{ }^{2} \\
\text { Quadriceps muscle }\end{array}$ & $\begin{array}{l}\text { Complexes I (NADH: ferricyanide dehydrogenase), II (succinate } \\
\text { dehydrogenase), I and III (cytochrome c reductase), and IV (cytochrome c } \\
\text { oxidase) normal- note the complex V ATP synthase was not assayed; slight } \\
\text { reduction in the matrix enzyme citrate synthase. }\end{array}$ \\
\hline $\begin{array}{l}15 \text { yrs. } \\
10 \text { mos. }\end{array}$ & $\begin{array}{l}\text { Muscle biopsy, } \\
\text { Vastus lateralis } \\
\text { skeletal muscle }^{2}\end{array}$ & $\begin{array}{l}\text { Mild to modest fiber size variability with overall smaller type } 1 \text { fibers. No } \\
\text { neurogenic changes or ragged red fibers. Modestly increased mitochondria on } \\
\text { EM }\end{array}$ \\
\hline $\begin{array}{l}18 \text { yrs. } \\
2 \text { mos. }\end{array}$ & $\begin{array}{l}\text { Repeat muscle } \\
\text { biopsy, quadriceps } \\
\text { muscle }^{3}\end{array}$ & $\begin{array}{l}\text { Normal histological morphology without myopathic or neurogenic changes, } \\
\text { normal myofibrillar mitochondria morphology and distribution; ATPase stain } \\
\text { at pH 4.3--occasional scattered type IIc fibers with no fiber type deficiency. }\end{array}$ \\
\hline $\begin{array}{l}18 \text { yrs. } \\
8 \text { mos. }\end{array}$ & Blood tests $^{4}$ & $\begin{array}{l}\text { Carnitine-24 total ( } 31-78 \text { normal), } 15 \text { free }(22-63 \text { normal) in micromoles per } \\
\text { milliliter, esterified to free ratio was } 0.6 \text { ( } 0.1-0.9 \text { normal. } \\
\text { Plasma lactate } 1728 \text { ( } 600-2600 \text { normal) and pyruvate } 117 \text { (20-140 normal) in } \\
\text { micromoles per liter; lactate/pyruvate ratio } 14.7 \text { at rest }\end{array}$ \\
\hline $\begin{array}{l}18 \text { yrs. } \\
8 \text { mos. }\end{array}$ & Urine test ${ }^{4}$ & $\begin{array}{l}\text { Selected organic acids succinate, 3-hydroxybutyrate, acetoacetate, glutarate-all } \\
\text { normal }\end{array}$ \\
\hline $\begin{array}{l}18 \text { yrs. } \\
8 \text { mos. }\end{array}$ & $\begin{array}{l}\text { Nonischemic } \\
\text { forearm exercise } \\
\text { testing results } \\
\text { (right arm })^{4}\end{array}$ & $\begin{array}{l}\text { Able to maintain grip at } 50 \% \text { maximal strength for } 45 \text { seconds, unable to } \\
\text { maintain } 75 \% \text { of maximum grip during that interval } \\
\text { Blood ammonia levels were normal at baseline with normal exercise increase; } \\
\text { plasma lactate levels were normal at baseline with a slightly exaggerated } \\
\text { 5.2-fold exercise increase; oxygen utilization was decreased throughout, } \\
\text { suggesting deficiency of oxidative-phosphorylation and attempts to use } \\
\text { alternative pathways like glycolysis for energy production before and after } \\
\text { exercise. }\end{array}$ \\
\hline
\end{tabular}

${ }^{1}$ GeneDx Company; ${ }^{2}$ Baylor College of Medicine ${ }^{3}$ Children's Health, Dallas TX; ${ }^{4}$ Neuromuscular unit, Houston Methodist, Houston TX--blood and urine measures performed by ARUP laboratories, Salt Lake City UT;

${ }^{5}$ Gnomad database, https://gnomad.broadinstitute.org/; c., DNA change; p., protein change, Arg, arginine amino acid; Asp, aspartate amino acid; Cys, cysteine amino acid; Glu, glutamate amino acid; His, histidine amino acid; mos., months; Mt or MT, mitochondrial; NADH, nicotinamide adenine dinucleotide, reduced form; yrs., years. 
Her symptoms worsened around age 15 years with severe fatigue that worsened as the day progressed and pulmonary symptoms that resembled reactive airway disease. She has some evidence of skin fragility with early striae, ovarian cysts with bladder issues (frequency), and neuromuscular symptoms including numbness and tingling, muscle aches, and feelings of muscle weakness in her extremities. Constipation, bloating, difficulty swallowing, and nausea were symptoms of irritable bowel syndrome and there were many of postural orthostatic tachycardia syndrome (fatigue, sleep difficulties, brain fog, heat-cold sensitivity, abnormal sweating, tachycardia, and foot discoloration on standing). She also reported the transient rashes, reactive skin, shortness of breath, and food-medication intolerances suggestive of mast cell activation disorder and had received that diagnosis. Findings not typical of EDS included paralysis of the left hemidiaphragm, thyroglossal duct cyst, and sacralization of the lumbosacral spine.

After finding the mitochondrial MT-ATP6 gene change, the patient had the additional laboratory studies summarized in Table 1, benefitting somewhat from a mitochondrial supplement "cocktail" with carnitine, ubiquinone, lipoic acid, and B vitamins combined with hydration, salt supplementation, and other therapies for her dysautonomia.

Physical examination documented 16 of 40 typical findings of EDS, a number at the 40th centile for 596 women systematically evaluated for EDS (Wilson, 2019b). She had tall stature with a height of 66 inches $\left(75^{\text {th }}\right.$ centile for age) and somewhat low weight $121 \mathrm{lb}$ (30th centile for age) for height that often occurs with irritable bowel issues. Other positive findings were an angular build, long arm span (1 inch more than her height), soft and elastic skin with unusual, white-surfaced scars, unusual forward neck curve, lower muscle mass and strength. She could only do 3 of the 9 Beighton maneuvers (knee hyperextension, touching palms to the floor) but showed mobility of larger joints by joining hands, one over shoulder/one around back, performing the prayer sign behind her back, and reaching her hand behind and around her back to touch her umbilicus.

Family history shows the following individuals with some symptoms of EDS-dysautonomia including her brother age 18 with colic, back and joint pain, striae, gastrointestinal issues, tics, and anxiety. Her mother is not flexible and had joint pain only later-she has the filamin A (FLNA) and ATPase (ATP1A2) gene changes shown in Table 1. Her father has muscle pain, dry skin, GI symptoms, fatigue, and anxiety that may be related to his procollagen lysyl oxidase (PLOD1) gene change shown in Table 1; he has a brother with Meniere's disease and allergies. Mother has many siblings including a sister and niece with several findings of EDS, having other sisters and nieces with gastrointestinal issues and striae. The maternal grandfather had blood clots with pulmonary embolism at a young age and the maternal grandmother had young-looking skin, mitral valve prolapse, and a heat stroke at age 13. Presence of multiple EDS symptoms on both sides of the family is consistent with multifactorial determination that includes genes of major effect exhibiting autosomal dominant inheritance. This interpretation would suggest lower penetrance for EDS in the mother despite genetic liability shown by her relatives' EDS symptoms. 


\section{Laboratory findings}

The patient had several laboratory findings typical of EDS (Wilson, 2019b) including low bone density with low vitamin D, thyroid, and iron levels. She had unusual pulmonary symptoms with diagnoses of central sleep apnea, paradoxical breathing, and dyspnea that benefitted from a bilevel positive airway pressure machine and oxygen therapy. Findings relevant to mitochondrial dysfunction are shown in Table 1, beginning with the DNA variant in the sixth component of the mitochondrial ATP synthase gene (MT-ATP6--Burrage, et al., 2014) that was qualified as likely pathogenic by GeneDx. There were three variants in nuclear genes that were not considered significant but could have made some contribution to EDS symptoms in the patient and her parents.

Mitochondrial DNA in skeletal muscle was shown to be slightly deficient by PCR amplification (93\% of controls) and by levels of the matrix enzyme citric acid synthase; however, mitochondrial numbers and morphology appeared normal in two muscle biopsies (Table 1). Mitochondrial respiratory complexes as measured by component enzyme activities were normal, although the final step of oxygen-ATP coupling, the ATPase synthase comprising complex V, was not assayed. Carnitine, a key molecule for mitochondrial transport, was slightly deficient while plasma lactate and pyruvate levels were normal at rest. Metabolic changes during forearm muscle exercise testing suggested mild mitochondrial respiratory chain dysfunction and demonstrated muscle weakness consistent with that noted on clinical evaluation. The first muscle biopsy at age 15 years, 10 months showed fiber size variability with smaller type 1 fibers while a second at age 18 years, 2 months did not. Correlating with the patient's lack of eye or encephalopathic changes was the lack of evidence for severe mitochondrial dysfunction as would be shown by strikingly elevated lactic acid, abnormal organic acids, or ragged red muscle fibers (Alston, et. al., 2017).

\section{EDS finding profiles in the patient and her peers}

The patient had characteristic findings of the arthritis-adrenaline disorder category that includes EDS as diagrammed in Fig. 1 and detailed in Table 2. The 80 history and 40 physical standardized findings of EDS (Wilson, 2019b) were condensed into 48 entries within 8 tissue laxity or vascular-dysautonomia categories, some entries combining several two or more related findings to increase reliability of group data. Examples include early clumsiness shown by toddlers with frequent falls in $22 \%$ of teens and later clumsiness in $44 \%$, averaged to a composite $33 \%$ for clumsiness overall. Important for the patient's low hypermobility score by the Beighton scale is large joint mobility, the $76 \%$ in teens an average of 6 percentages--78\%-78\% for right and left elbow hyperextension, 76\%-63\% for knee hyperextension, $80 \%-76 \%$ for joining hands and making the prayer sign behind the back.

The 48 entries include 74 of 80 history and 22 of 40 physical findings from the standard evaluation forms (Wilson, 2019b), registered as positive or negative for the patient and calculated from positive percentages for her teen peer group (Table 2). The patient had slightly fewer lax tissue findings in those 4 categories but equal or slightly more findings in the vascular-dysautonomia categories. Overall congruence is supported by the 19 total lax tissue findings in the patient versus 21 in her teen peers and the 18 total vascular and 


\section{$\triangle$ Macrothink}

dysautonomia findings in the patient versus 15 in her peers (last row, Table 2). Of the 37 of 74 positive findings in the patient, 27 were purely historical while 10 included physical findings.

Table 2. Comparison of tissue laxity and dysautonomia findings in the patient and peers

\begin{tabular}{|c|c|c|c|c|c|}
\hline Finding (number averaged) & Teens $^{1}$ & $\mathrm{Pt}$ & Finding (number averaged) & Teens $^{1}$ & $\mathrm{Pt}$ \\
\hline \multicolumn{3}{|l|}{ Lax tissue finding } & \multicolumn{3}{|l|}{ Vascular-dysautonomia } \\
\hline Lax-joints (14) & $8.3 / 14^{2}$ & $8 / 14$ & Vascular/pooling (6) & $2.2 / 6$ & $3 / 6$ \\
\hline Infant flexibility (1) & $50 \%$ & - & Dizziness (1) & $91 \%$ & - \\
\hline Clumsy early-late (2) & $33 \% \%^{2}$ & $-1+$ & Syncope (1) & $31 \%$ & - \\
\hline Aware-DJ tricks $(2)^{3}$ & $45 \%$ & $+/+$ & Foot discoloration $(1)^{5}$ & $56 \%$ & + \\
\hline Subluxations-sprains (2) & $55 \%$ & $+/-$ & Bladder issues (1) & $25 \%$ & + \\
\hline Beighton $>6$ of $9(1)$ & $57 \%$ & - & Hernia $(1)^{6}$ & $13 \%$ & - \\
\hline $\begin{array}{l}\text { Large joint Knee/Elbow (4) } \\
\text { Hand join/Pray }(2)^{4}\end{array}$ & $76 \%{ }^{2}$ & $+/+/-/-+/+$ & Heart disease $(1)^{7}$ & $6.0 \%$ & + \\
\hline Lax-Injuries (7) & $3.8 / 7$ & $3 / 7$ & Dysautonomia-Neurologic (10) & $4.0 / 10$ & $4 / 10$ \\
\hline Early pain/limited (2) & $61 \%$ & $-/+$ & Migraines/ daily headaches (2) & $61 \%$ & - \\
\hline TMJ issues $(1)$ & $34 \%$ & - & Chiari deformation (1) & $3.3 \%$ & - \\
\hline Joint pain (1) & $97 \%$ & + & Balance difficulties $\mathrm{Hx} / P E(2)$ & $38 \%$ & $-/-$ \\
\hline Fractures (1) & $56 \%$ & + & Numbness-Neuropathy (2) & $39 \%$ & $+/-$ \\
\hline Joint procedures (1) & $60 \%$ & - & Muscle aches & $56 \%$ & + \\
\hline Spinal disc issues (1) & $9.0 \%$ & - & Muscle weakness $\mathrm{Hx} / P E(2)$ & $32 \%$ & $+/+$ \\
\hline Lax-deformations (12) & $4.1 / 12$ & $5 / 12$ & Dysautonomia-IBS/MCAD (8) & $4.0 / 8$ & $5 / 8$ \\
\hline Tall/long wingspan (2) & $30 \%$ & $+/+$ & Gum disease-recession (1) & $6.2 \%$ & - \\
\hline Long face/braces (2) & $56 \%$ & $-1+$ & Constipation-diarrhea (1) & $69 \%$ & + \\
\hline Long fingers/WM sign (2) & $41 \%$ & $-/-$ & Bloating-reflux/nausea (2) & $68 \%$ & $+/+$ \\
\hline Scoliosis Hx/PE (2) & $35 \%$ & $+/-$ & Rashes/Hives-reactive skin (2) & $40 \%$ & + \\
\hline Pectus Hx/PE (2) & $4.7 \%$ & $+/-$ & Asthma-shortness of breath (1) & $34 \%$ & + \\
\hline Flat feet $\mathrm{Hx} / P E(2)$ & $36 \%$ & $-/-$ & Food-medicine intolerances (1) & $75 \%$ & + \\
\hline Lax-skin (9) & $5.1 / 9$ & $3 / 9$ & Dysautonomia-POTS (8) & $4.9 / 8$ & $6 / 8$ \\
\hline Soft-velvety skin (1) & $97 \%$ & + & Chronic fatigue (1) & $88 \%$ & + \\
\hline Bruise easily (1) & $69 \%$ & - & Intermittent tachycardia/anxiety (2) & $71 \%$ & $+/-$ \\
\hline Stria before pregnancy (1) & $81 \%$ & + & Sleep difficulties (1) & $41 \%$ & + \\
\hline Elastic skin $\mathrm{Hx} / 2 P E(3)$ & $56 \%$ & $-/+/-$ & Brain fog-poor focus (1) & $66 \%$ & + \\
\hline Epidermal stretch folds (1) & $22 \%$ & - & Heat sensitive/Abnormal sweating (2) & $46 \%$ & $+/+$ \\
\hline Unusual scars $\mathrm{Hx} / P E(2)$ & $35 \%$ & $-/-$ & Salt fancy (1) & $56 \%$ & - \\
\hline \multirow[t]{2}{*}{ Lax tissue total (42) } & $21 / 42$ & $19 / 42$ & Vascular-Dysautonomia total & $15 / 32$ & $18 / 32$ \\
\hline & & $10 \mathrm{H} \mathrm{9P}$ & & & $17 \mathrm{H} 1 \mathrm{P}$ \\
\hline
\end{tabular}

Compared are 42 laxity findings, 20 physical (PE - in italics) and 32 vascular-dysautonomia findings (2 physical), + indicating a findings presence in the patient and - its absence. ${ }^{1}$ Finding percentages in 32 teens diagnosed with EDS by standard evaluation; ${ }^{2}$ composite findings like the $33 \%$ average for 2 early and late clumsiness findings or the $76 \%$ average for 6 large joint findings require appropriate multiplication of those percentages ( 2 or $\times 6$ ) to calculate the average number of findings a teenage EDS female would have (e. g., 8.3 of 14 in the lax joint category); ${ }^{3}$ recognizing their hypermobility or doing double-jointed (DJ) tricks; ${ }^{4}$ bilateral elbow/knee extension of the Beighton scale, joining hands one over shoulder other around back, prayer sign behind back show large joint mobility; ${ }^{5}$ red-blue color after standing several minutes; ${ }^{6}$ umbilical, inguinal, or pelvic collapse; 7 added percentages of valvular regurgitation(4.1), vessel dilation/aneurysm (0), or arrhythmia (1.9); IBS, irritable bowel 
syndrome; MCAD, mast cell activation disorder; POTS, postural orthostatic tachycardia syndrome; WM, Walker-Murdoch sign of overlapping thumb and little finger around wrist.

The greatest discrepancies included several categories where the patient had lower numbers of findings-- 3 versus a calculated 5.1 of 9 findings for her teen peers in the lax-skin, 3 versus 3.8 of 7 in the lax-injury, and 8 versus 8.3 of 14 in the lax-joint categories. Patient excesses included 5 versus 4.1 of 12 in the lax-deformation, 3 versus 2.2 om the vascular/pooling, 5 versus 4.0 in the dysautonomia-IBS/MCAD, and 6 versus 4.9 in the dysautonomia-POTS categories. These excesses and equality in the dysautonomia-neurologic category (4 positive for the patient versus 4.0 of 10 for her average peer) fit with previously known effects of genes altering mitochondrial function as discussed below.

\section{Discussion}

Novel association of genes with disease through genomic analyses unbiased by symptomatic targeting is particularly enlightening for complex, common, and multifactorial disorders like autism (Wilson and Tonk, 2018) or EDS (Wilson, 2018). Problems compromising the application of these remarkable genome-screening technologies include the interpretation of molecular change as well as its key complement, the matching of DNA variants with appropriate disease entities. Overemphasis on functional analyses that may not be available in the affected patient tissue or replicate in vivo physiologic mechanisms hampers one side of variant interpretation while focus on symptom rather than syndrome plagues the other. Recurring gene change in affected rather than normal people provides candidacy for a DNA variant's significance, its election optimized by clinical correlation rather than cellular studies (Wilson, 2019a).

Recall how recurring chromosome 15 deletion in Prader-Willi syndrome prompted correlation despite ignorance of how haploinsufficiency might cause this complex pattern (Cassidy, et al., 2012). Complete characterization of a phenotype that included physical changes like pale eyes or hypotonia and behavioral changes like hyperphagia allowed correlation with effects of genes within the deletion interval. Clinical then molecular studies elucidated genotype-phenotype correlations and explained why a comparable deletion on the maternally derived chromosome caused the vastly different Angelman syndrome. A parallel approach to results of genomic analyses would recognize gene changes as candidates for further collaborative studies between molecular geneticists and experienced physicians. Discard of DNA data because of functional ignorance would have left Prader-Willi as an ill-defined obesity condition, just as molecular qualification of most DNA change as of uncertain significance has led to rejection of genomic technology by the very physicians needed to interpret it (Hunter and Drazen, 2019).

EDS began as a disorder of joint and skin elasticity, then was joined with others in a connective tissue dysplasia category, now split into types with narrow diagnostic criteria (Malfait, et al., 2017) that omit its equally obvious and treatable behavioral traits (Wilson, 2015; Wilson, 2019a,b). Autonomic imbalance arises even with benign joint laxity (Gazit, et al., 2003), its adrenergic stimulation that causes fatigue, fainting, bowel distress, and exuberant cardiovascular and allergy responses being the presenting complaint in $75 \%$ of 
affected teens (Wilson, 2019b). Complete evaluation of EDS and its dysautonomia symptoms using standard forms shows that findings of lax tissue and adrenergic imbalance occur in all EDS patients, those of any age, severity, type, or specialty referral source (Wilson, 2019b).

The arthritis-adrenaline disorder finding pattern documented in Table 2 for our patient and her peer group is seen again and again in EDS if properly looked for, common types like hypermobile or classical EDS showing overlap for all but a few findings. Not discussed here are more severe types like vascular or periodontal EDS (Wilson, et al., 2020) with more risk for vascular, bowel, or uterine ruptures on a similar tissue laxity-dysautonomia background. Emphasis of type over mechanism causes these severe disorders to hover like specters over patients despite their extreme rarity ( 1 or 2 of 1656 EDS clinic evaluations--Wilson, 2019b).

The mitochondrial ATP synthetase is a complex of 12-18 subunits, 10-16 being encoded by the nuclear genome and 2 (subunits 6 and 8) by the mitochondrial genome (Burrage, et al., 2014). The mitochondrial DNA change in the ATP synthetase gene of complex V in our patient caused the typical arthritis-adrenaline disorder pattern of findings as documented in Table 2. Her clinical profile was similar to the neurologic and dysautonomia findings manifest by 32 peer teen females, the fewer joint and skin laxity findings supporting neuromuscular influence of the mitochondrial DNA change in our patient.

The MT-ATP6 nucleotide change occurs in a conserved region of the encoded protein, makes a significant change in amino acid structure with rare occurrence in normal databases, and for those reasons was qualified as likely disease-contributing (pathogenic). Its presence in $32 \%$ of leucocyte mitochondria may be higher in muscle, the laboratory studies in Table 1 suggesting some degree of mitochondrial dysfunction in that tissue. Although some mutations in the MT-ATP gene have caused severe mitochondrial diseases like Leigh syndrome (Alston, et al., 2017), our patient clearly has a different phenotype that is more compatible with EDS.

Genetic correlation of this unexpected mitochondrial DNA change with EDS is supported by the ability of some mitochondrial polymerase gamma ( $P O L G)$ gene changes to cause neurologic/autonomic disease (Stewart, et al., 2009) and others to cause EDS-dysautonomia (Wilson, 2019a). Polygenic influence on EDS could accommodate contribution of the patient's maternal filamin A (FLNA) gene-- associated with lung, bowel, bone, and brain disorders (Reinstein, et al., 2013)--to her and her mother's symptoms, a contribution diminished by the moderation of $\mathrm{X}$ chromosome loci in females. Although the lysyl oxidase PLOD1 gene has required alteration of both copies to cause an EDS-like pattern (Voermans, et al., 2009), it is possible that enzymes processing macromolecular substrates like procollagens may require full activity for effective action, the heterozygous deficiency contributing to symptoms in the patient and her father. Also possible is contribution of the ATPase (ATP1A2) gene change (Schack, et al., 2012) that would be expressed in muscle, though the patient did not have its associated hemiplegic and migraine symptoms.

Besides a genomic perspective that expects multiple candidate genes in common disorders, a clinical perspective on the mechanism by which these many genes can cause EDS-dysautonomia is necessary. Emerging genomic data (Wilson, 2019a) suggests that genes impacting several connective tissue elements--the skin exoskeleton and muscle armature that 
encapsulate connective tissue, the infiltrating nerves and vessels that message this medium, the bone substructure that gives it inner support--should be added to recognized collagen genes affecting joints and matrix as causes of an arthritis-adrenaline disorder/EDS category. Certain MT-ATP6 gene changes could impact neuromuscular elements to cause tissue and autonomic irregularity, the latter cycling to influence the former as evidenced by small (autonomic) fiber neuropathy (Cazzato and Lauria, 2017) in EDS and the patients with tissue laxity arising from tryptase gene expansion (Lyons, et al., 2016). Gene changes affecting mitochondria should join those affecting collagen genes (Wilson, 2019a) as potential determinants of the arthritis-adrenaline finding pattern outlined in Table 2.

\section{Conclusions/Final Remarks}

A patient with a DNA sequence change in a mitochondrial gene (MT-ATP6), slightly altered oxygen utilization during exercise testing, and typical findings of EDS is presented as evidence that mild mitochondrial dysfunction can contribute to the arthritis-adrenaline disease category. This preliminary observation must be validated by study of more patients with EDS and mitochondrial DNA variation, a possibility supported by the 96 patients with EDS and mitochondrial DNA change reported previously (Wilson, 2019a). Requisite for such studies is thorough documentation of autonomic findings that have been underemphasized in EDS, alterations explained by the cyclical articulo-autonomic dysplasia processes that are diagrammed in Fig. 1. The importance of autonomic imbalance in EDS pathogenesis is demonstrated by the present patient, by the ability of mast cell-associated tryptase activation to produce tissue laxity (Lyons, et al., 2016), and by the mitochondrial polymerase gamma gene alterations that can cause EDS (Wilson, 2019a) or a neurogastrointestinal disorder dominated by autonomic dysfunction (Stewart, et al., 2008).

\section{References}

Alston, C. L., Rocha, M. C., Lax, N. Z., Turnbull, D. M., \& Taylor, R. W. (2017). The genetics and pathology of mitochondrial disease. Journal of Pathology, 241(2), 236-250. https://doi.org/10.1002/path.4809

Burrage, L. C., Tang, S., \& Wang, J., et al. (2014). Mitochondrial myopathy, lactic acidosis, and sideroblastic anemia (MLASA) plus associated with a novel de novo mutation (m.8969G-A) in the mitochondrial encoded ATP6 gene. Molecular Genetics and Metabolism, 113, 207-212. https://doi.org/10.1016/j.ymgme.2014.06.004

Cassidy, S. B., Schwartz, S., Miller, J. L., \& Driscoll, D. J. (2012). Prader-Willi syndrome. Genetic Medicine, 14(1), 10-26. https://doi.org/10.1038/gim.0b013e31822bead0

Cazzato, D., \& Lauria, G. (2017). Small fibre neuropathy. Current Opinions in Neurology, 30, 490-499. https://doi.org/10.1097/WCO.0000000000000472

Gazit, Y., Nahir, A. M., Grahame, R., \& Jacob, G. (2003). Dysautonomia in the joint hypermobility syndrome. American Journal of Medicine, 115, 33-40. https://doi.org/10.1016/S0002-9343(03)00235-3

Hunter, D. J., \& Drazen, J. M. (2019). Has the genome granted our wish yet? New England 
Journal of Medicine, 380, 2391-2393. https://doi.org/10.1056/NEJMp1904511

Lyons, J. J., Dietz, H. C., \& Sleeper, L. A. et al. (2016). Elevated basal serum tryptase identifies a multisystem disorder associated with increased TPSAB1 copy number. Nature Genetics, 48, 1564-1569. https://doi.org/10.1038/ng.3696

Malfait, F., Francomano, C., \& Byers, P., et al. (2017). The 2017 international classification of the Ehlers-Danlos Syndromes. American Journal of Medical Genetics Part C Seminars in Medical Genetics, 175C, 5-7. https://doi.org/10.1002/ajmg.c.31552

Reinstein, E., Frentz, S., \& Morgan, T., et al. (2013). Vascular and connective tissue anomalies associated with X-linked periventricular heterotopia due to mutations in filamin A. European Journal of Human Genetics, 21, 494-502. https://doi.org/10.1038/ejhg.2012.209

Schack, V. R., Holm, R., \& Vilsen, B. (2012). Inhibition of phosphorylation of Na+, $\mathrm{K}+$-ATPase by mutations causing familial hemiplegic migraine. Journal of Biological Chemistry, 287, 2191-2202. https://doi.org/10.1074/jbc.M111.323022

Stewart, J. D., Tennant, S., \& Powell, H., et al. (2009). Novel POLG1 mutations associated with neuromuscular and liver phenotypes in adults and children. Journal of Medical Genetics, 46, 209-214. https://doi.org/10.1136/jmg.2008.058180

Teer, J. K., \& Mullikin, J. C. (2010). Exome sequencing: the sweet spot before whole genomes. Human Molecular Genetics, 19, R145-R151. https://doi.org/10.1093/hmg/ddq333

Tinkle, B. T., \& Levy, H. P (2019). Symptomatic joint hypermobility: The hypermobile type of Ehlers-Danlos syndrome and the hypermobility spectrum disorders. Medical Clinics of North America, 103, 1021-1033. https://doi.org/10.1016/j.mcna.2019.08.002

Voermans, N. C., Bonnemann, C. G., Lammens, M., van Engelen, B. G., \& Hamel, B. C. J. (2009). Myopathy and polyneuropathy in an adolescent with the kyphoscoliotic type of Ehlers-Danlos syndrome. American Journal of Medical Genetics Part A, 149A, 2311-2316. https://doi.org/10.1002/ajmg.a.32997

Weerakkody, R. A., Vandrovcova, J., \& Kanonidau, C., et al. (2016). Targeted next-generation sequencing makes new molecular diagnoses and expands genotype-phenotype relationship in Ehlers-Danlos syndrome. Genetics in Medicine, 18, 1119-1127. https://doi.org/10.1038/gim.2016.14

Wilson, G. N (2015). Common tragedies of lax joint syndromes: Broken hearts, fallen men, and loose women. Consultant, 55, 102-110.

Wilson, G. N. (2014). Exome sequencing analysis of connective tissue dysplasia: Death and rebirth of clinical genetics? American Journal of Medical Genetics Part A, 164A, 1209-1212. https://doi.org/10.1002/ajmg.a.36463

Wilson, G. N. (2018). Joint Laxity/Hypermobility: Old Problems and New Opportunities for Family Mam Medicine. Care, http://www.oatext.com/joint-laxity-hypermobility-old-problems-and-new-opportunities-for-fa 
mily-medicine.php, 2018.

Wilson, G. N. (2019b). Clinical analysis supports articulo-autonomic dysplasia as a unifying pathogenic mechanism in Ehlers-Danlos syndrome and related conditions. The Journal of Biosciences and Medicine, 7, 149-168. https://doi.org/10.4236/jbm.2019.76010

Wilson, G. N., \& Tonk, V. S. (2018). Autism: A different vision. Open Journal of Psychiatry, 8, 263-296. www.scirp.org/journal/PaperInforCitation.aspx?PaperID=86157

Wilson, G. N., Tonk, S. S., Tonk, V. S., \& Lampe, R. (2020). Complement gene mutation and Ehlers-Danlos syndrome. The Journal of Biosciences \& Medicine, 8, 28-36. https://doi.org/10.4236/jbm.2020.86003

Wilson, G.N. (2019a). Genomic analysis of 727 patients with Ehlers-Danlos syndrome I: Clinical perspective relates 23 genes to a maternally influenced arthritis-adrenaline disorder. The Journal of Biosciences and Medicine, 7, 181-204. https://doi.org/10.4236/jbm.2019.712015

Yang, Y., Muzny, D. M., \& Reid JG, et al. (2013). Clinical whole-exome sequencing for the diagnosis of mendelian disorders. New England Journal of Medicine, 369, 1502-1511. https://doi.org/10.1056/NEJMoa1306555

\section{Copyright Disclaimer}

Copyright for this article is retained by the author(s), with first publication rights granted to the journal.

This is an open-access article distributed under the terms and conditions of the Creative Commons Attribution license (http://creativecommons.org/licenses/by/4.0/). 